University of Wollongong

Research Online

Australian Institute for Innovative Materials -

Papers

Australian Institute for Innovative Materials

$1-1-2014$

Hollow MnCo204 submicrospheres with multilevel interiors: From mesoporous spheres to yolk-in-double-shell structures

\author{
Jingfa Li \\ University of Wollongong \\ Jiazhao Wang \\ University of Wollongong, jiazhao@uow.edu.au \\ Xin Liang \\ University of Wollongong, x|475@uowmail.edu.au \\ Zhijia Zhang \\ University of Wollongong, zz755@uowmail.edu.au \\ Hua-Kun Liu \\ University of Wollongong, hua@uow.edu.au
}

See next page for additional authors

Follow this and additional works at: https://ro.uow.edu.au/aiimpapers

Part of the Engineering Commons, and the Physical Sciences and Mathematics Commons

Research Online is the open access institutional repository for the University of Wollongong. For further information contact the UOW Library: research-pubs@uow.edu.au 


\title{
Hollow MnCo204 submicrospheres with multilevel interiors: From mesoporous spheres to yolk-in-double-shell structures
}

\author{
Abstract \\ We present a general strategy to synthesize uniform MnCo204 submicrospheres with various hollow \\ structures. By using MnCo-glycolate submicrospheres as the precursor with proper manipulation of \\ ramping rates during the heating process, we have fabricated hollow MnCo2O4 submicrospheres with \\ multilevel interiors, including mesoporous spheres, hollow spheres, yolk-shell spheres, shell-in-shell \\ spheres, and yolk-in-double-shell spheres. Interestingly, when tested as anode materials in lithium ion \\ batteries, the MnCo2O4 submicrospheres with a yolk-shell structure showed the best performance \\ among these multilevel interior structures because these structures can not only supply a high contact \\ area but also maintain a stable structure.

\section{Keywords} \\ interiors, multilevel, spheres, yolk, mesoporous, double, hollow, shell, structures, submicrospheres, \\ mnco2o4 \\ Disciplines \\ Engineering | Physical Sciences and Mathematics

\section{Publication Details} \\ Li, J., Wang, J., Liang, X., Zhang, Z., Liu, H., Qian, Y. \& Xiong, S. (2014). Hollow MnCo2O4 submicrospheres \\ with multilevel interiors: From mesoporous spheres to yolk-in-double-shell structures. ACS Applied \\ Materials and Interfaces, 6 (1), 24-30.

\section{Authors} \\ Jingfa Li, Jiazhao Wang, Xin Liang, Zhijia Zhang, Hua-Kun Liu, Yitai Qian, and Shenglin Xiong
}




\title{
Hollow $\mathrm{MnCo}_{2} \mathrm{O}_{4}$ Submicrospheres with Multilevel Interiors: From Mesoporous Spheres to Yolk-in-Double-Shell Structures
}

Jingfa Li, ${ }^{\text {ab }}$ Jiazhao Wang, ${ }^{\text {a }}$ Xin Liang, ${ }^{\text {a }}$ Zhijia Zhang, ${ }^{\text {a }}$ Huakun Liu, ${ }^{\text {a }}$ Yitai Qian ${ }^{\text {bc }}$ and Shenglin $\mathrm{Xiong}^{\mathrm{bc} *}$

${ }^{\mathrm{a}}$ Institute for Superconducting and Electronic Materials, University of Wollongong, Wollongong, NSW, 2522, Australia.

${ }^{\mathrm{b}}$ Key Laboratory of the Colloid and Interface Chemistry (Shandong University), Ministry of Education, and School of Chemistry and Chemical Engineering, Shandong University, Jinan, Shandong, 250100, P. R. China.

${ }^{\mathrm{c}}$ Hefei National Laboratory for Physical Science at Microscale and Department of Chemistry, CAS Key Laboratory of Materials for Energy Conversion, University of Science and Technology of China, Hefei, Anhui, 230026, P. R. China.

\begin{abstract}
We present a general strategy to synthesize uniform $\mathrm{MnCo}_{2} \mathrm{O}_{4}$ submicrospheres with various hollow structures. By using MnCo-glycolate submicrospheres as the precursor with proper manipulation of ramping rates during the heating process, we have fabricated hollow $\mathrm{MnCo}_{2} \mathrm{O}_{4}$ submicrospheres with multilevel interiors, including mesoporous spheres, hollow spheres, yolk-shell spheres, shell-in-shell spheres and yolk-in-double-shell spheres. Interestingly, when tested as anode materials in lithium ion batteries, the $\mathrm{MnCo}_{2} \mathrm{O}_{4}$ submicrospheres with a yolk-shell structure showed the best performance among these multilevel interior structures because these structures can not only supply a high contact area but also maintain a stable structure.
\end{abstract}

Keywords: complex hollow structures; binary metal oxides; heterogeneous contraction 
In recent years, complex hollow micro-/nanoscale structures with controlled size, shape and interior architecture are of great interest, as these structures are expected to offer more handles to tailor the properties for different applications such as catalysis, ${ }^{1}$ photocatalysis, ${ }^{2}$ drug delivery, ${ }^{3}$ and lithium ion batteries. ${ }^{4}$ Various methodologies have been developed to achieve this special nanostructure. ${ }^{5-8}$ Heterogeneous contraction, for example, is a typical and effective route for controlled synthesis of hollow structure with different interiors, which is caused by non-equilibrium heat treatment and determined by the difference between the cohesive force and the adhesive force generated by a high heating rate. In particular, metal oxides have been investigated mostly and a number of inorganic hollow structures have been synthesized by this approach. For instance, delicate $\gamma-\mathrm{Fe}_{2} \mathrm{O}_{3}, \alpha-\mathrm{Fe}_{2} \mathrm{O}_{3}$, and $\mathrm{ZnO}$ multi-shelled hollow spheres, have been prepared by calcining the solid microsphere precursors through the heterogeneous contraction process. ${ }^{9-11}$ Lou and co-authors have reported binary metal oxides like $\mathrm{ZnMn}_{2} \mathrm{O}_{4}$ hollow microspheres, ${ }^{12}$ double-shelled $\mathrm{CoMn}_{2} \mathrm{O}_{4}$ hollow microcubes, ${ }^{13}$ and $\mathrm{ZnMn}_{2} \mathrm{O}_{4}$ ball-in-ball hollow microspheres by this method. ${ }^{14}$ Our previous reports also mentioned the synthesis of spinel binary metal oxides including mesoporous $\mathrm{NiCo}_{2} \mathrm{O}_{4}$ microspheres, ${ }^{15} \mathrm{Mn}_{1.5} \mathrm{Co}_{1.5} \mathrm{O}_{4}$ core-shell microspheres, ${ }^{16}$ yolk-shelled $\mathrm{ZnCo}_{2} \mathrm{O}_{4}$ microspheres, ${ }^{17} \mathrm{CoMn}_{2} \mathrm{O}_{4}$ and $\mathrm{MnCo}_{2} \mathrm{O}_{4}$ quasi-hollow microspheres. ${ }^{18}$ However, the hollow structure is obtained as it is after calcinations and cannot be tuned because of the smaller weight loss. Therefore, it is still a great challenge to form the hollow structures for binary metal oxide with controlling interiors, despite of its popularity in simple metal oxide.

In this letter, we exploited the capacity of heterogeneous contraction process for forming binary metal oxide $\mathrm{MnCo}_{2} \mathrm{O}_{4}$ complex hollow structures and found that with proper manipulation of ramping rates (denoted as the $R$ value) during the heating process thus disturbing the balance between the cohesive force and the adhesive force, lead to the formation of mesoporous spheres, hollow spheres, yolk-shell spheres, shell-in-shell hollow spheres, and yolk-in-double-shell structures. As shown in Scheme 1, we will use the solid MnCo-glycolate submicrospheres as a precursor to establish some general principles in the hollowing process for fabrication of complex $\mathrm{MnCo}_{2} \mathrm{O}_{4}$ hollow spheres. More specifically, there exisits a temperature gradient $(\Delta T)$ for the MnCo-glycolate solid spheres along the radical direction in the initial heating period. When $\Delta T$ is very low ( $R$ value is 0.5 in this experiment), the solid spheres are almost homogeneously from the surface to the center and thus transfer into $\mathrm{MnCo}_{2} \mathrm{O}_{4}$ porous spheres with the mass loss of organic component. When $\Delta T$ is high ( $R$ value is no less than 1.0 in this experiment), the heating process are heterogeneous and non-equilibrium then two opposite directions of the cohesive $\left(\sigma_{\mathrm{co}}\right)$ and adhesive forces $\left(\sigma_{\mathrm{ad}}\right)$ exert at the interface of the $\mathrm{MnCo}_{2} \mathrm{O}_{4}$ shell and the composite yolk. When the $\sigma_{\text {ad }}$ exceeds $\sigma_{\text {co }}$ in high $\Delta T$, leading to the diffusion of the yolk into the shell and the formation of the $\mathrm{MnCo}_{2} \mathrm{O}_{4}$ hollow spheres. If the $\sigma_{\text {co }}$ exceeds $\sigma_{\text {ad }}$ in a large $\Delta T$, the inner yolk will detach from preformed shell by the continuing calcinations, thus resulting in various hollow spheres with multilevel interiors, depending on the $\Delta T$ from the $R$ value for the inner solid spheres. Interestingly, 
when tested as anode materials in lithium ion batteries, the $\mathrm{MnCo}_{2} \mathrm{O}_{4}$ submicrospheres with a yolk-shell structure showed the best performance among these multilevel interior structures because this structure can not only supply a high contact area but also maintain a stable structure.

The reaction of $\mathrm{Mn}\left(\mathrm{CH}_{3} \mathrm{COO}\right)_{2} \cdot 4 \mathrm{H}_{2} \mathrm{O}$ and $\mathrm{Co}\left(\mathrm{CH}_{3} \mathrm{COO}\right)_{2} \cdot 4 \mathrm{H}_{2} \mathrm{O}$ with polyvinyl pyrrolidone (PVP, $\mathrm{M}_{\mathrm{w}} \sim 1300000$ ) in ethylene glycol (EG) solvent at $170{ }^{\circ} \mathrm{C}$ can yield MnCo-glycolate, as indicated by the XRD pattern shown in Fig. S1 (Supporting Information; SI), which is characteristic of metal glycolate. ${ }^{19}$ The morphologies of the as-prepared carbonate precursors were investigated by field emission scanning electronic microscopy (FESEM) and transmission electron microscopy (TEM), and the panoramic views (Fig. S2; SI) revealed monodisperse solid sphere-like structures with the diameter of $\sim 300 \mathrm{~nm}$. The thermogravimetric analysis (TGA) curve of the precursor in Fig. 1(a) indicates that there are two major weight loss steps: the first weight loss below $200{ }^{\circ} \mathrm{C}$ is attributed to the loss of physically and chemically adsorbed ethylene glycol or other organic molecules, ${ }^{9}$ while the second prominent one is due to the thermal decomposition of the MnCo-glycolate into $\mathrm{MnCo}_{2} \mathrm{O}_{4}$. The differential TGA (DrTGA) curve shows a sharp exothermic peak at $274.2^{\circ} \mathrm{C}$, corresponding to the dominant mass loss (43.9 wt\%). The large weight loss indicates that the MnCo-glycolate consisted of a large fraction of species including $\mathrm{CH}_{3} \mathrm{COO}^{-}$, PVP, and partially polymerized EG. To ensure the complete decomposition of the precursor, we chose $400{ }^{\circ} \mathrm{C}$ as the calcination temperature for the synthesis of $\mathrm{MnCo}_{2} \mathrm{O}_{4}$. Interestingly, after calcining at different heating rates from 0.5 to $7^{\circ} \mathrm{C} / \mathrm{min}$ under atmosphere, spinel $\mathrm{MnCo}_{2} \mathrm{O}_{4}$ phases with different structures were obtained, as was confirmed by the X-ray diffraction patterns, which can be characterized as face-centered-cubic (fcc) $\mathrm{MnCo}_{2} \mathrm{O}_{4}$ (space group Fd3m (227); JCPDS no. 23-1237) indicated by the XRD patterns in Fig. 1(b).

Nitrogen sorption isotherms were collected to investigate the porous structure and the Brunauer-Emmett-Teller (BET) surface areas of these hollow structures with different interiors, and the results are shown in Fig. 1(c) and (d). All the isotherms are very similar and classified as type IV, with a type $\mathrm{H} 1$ hysteresis loop, indicating that these structures are mesoporous, ${ }^{20,21}$ while the areas of the loops are different, which reflects the different specific surface areas. The values of the BET surface areas are shown in Table S1 (Supporting Information), and the results indicate that the yolk-shell submicrospheres possess the largest surface area, while the mesoporous spheres possess the smallest one, although the latter one exhibits the narrowest pore size distribution, which is beneficial for maintaining the structure. These submicrospheres, with a hierarchical mesoporous structure, permit the electrolyte to easily penetrate through the mesopores and make close contact with the inner-outer surfaces of numerous primary particles, possibly resulting in a considerable improvement in the electrochemical properties. We also carried out X-ray photoelectron spectroscopy (XPS) of the hollow $\mathrm{MnCo}_{2} \mathrm{O}_{4}$ submicrospheres, as shown in Fig. S3 (SI). The results indicate that the solid-state redox couples $\mathrm{Mn}^{3+} / \mathrm{Mn}^{2+}$ and $\mathrm{Co}^{3+} / \mathrm{Co}^{2+}$ coexist in the structure, which is similar to what has been previously reported. ${ }^{18}$ The ratios are shown in Table S1 based on the areas of deconvoluted peaks. 
In contrast to the carbonate precursor reported in previous work, ${ }^{12-16,18}$ the MnCo-glycolate could yield a large weight loss due to the presence of a large amount of organic species by heating under atmosphere, the progress of which well controlled the different types of interiors. As commonly observed, the TEM and FESEM images in Fig. 2 indicate that the spheres obtained at different heating rates (from 0.5 to $7{ }^{\circ} \mathrm{C} / \mathrm{min}$ ) are various hollow structures with multilevel interiors, ranging from mesoporous to yolk-in-double-shell structures. Fig. 2(a) (from $\mathrm{a}_{1}$ to $\mathrm{a}_{2}$ ) shows that the mesoporous structures are obtained under the $\mathrm{R}$ value of $0.5^{\circ} \mathrm{C} / \mathrm{min}$. The diameters of the submicrospheres are $\sim 250 \mathrm{~nm}$, smaller than for the precursor due to the inward shrinkage during the calcination process. The SEM image in Fig. $2\left(\mathrm{a}_{3}\right)$ indicates that the submicrospheres are also uniform and their surfaces are rough, demonstrating the porous structure due to the release of the organic component. When $R$ is increased to $1^{\circ} \mathrm{C} / \mathrm{min}$, obvious hollow submicrospheres are produced (Fig. 2(b $\left.\left.\mathrm{b}_{1}-\mathrm{b}_{3}\right)\right)$ with shell thickness of $\sim 70 \mathrm{~nm}$. The FESEM image in Fig. 2(b $\left.\mathrm{b}_{3}\right)$ clearly shows several broken sphere-like particles with a hollow cavity. The yolk-shell structures are fabricated under the $R$ value of $2{ }^{\circ} \mathrm{C} / \mathrm{min}$, as indicated in Fig. 2( $\left.\mathrm{c}_{1}\right)$. The high magnification TEM image shows that the particles are composed of a thin shell with a dense yolk in diameter of 150 $\mathrm{nm}$. A cracked submicrosphere fragment further confirms the formation of yolk-shell structures in Fig. 2( $\mathrm{c}_{3}$ ). When $R$ rises to $5{ }^{\circ} \mathrm{C} / \mathrm{min}$, shell-in-shell hollow spheres with very thin walls ( $\sim 20 \mathrm{~nm}$ ) are obtained in Fig. $2\left(d_{1}-d_{2}\right)$. The FESEM image in Fig $2\left(d_{3}\right)$ clearly shows the hollow structures with double shells. Fig. $2\left(\mathrm{e}_{1}\right)$ and $\left(\mathrm{e}_{2}\right)$ demonstrate that more complicated yolk-in-double-shell structures form when the $R$ value is increased to $7^{\circ} \mathrm{C} / \mathrm{min}$. From the FESEM image (Fig. 2( $\left.\mathrm{e}_{3}\right)$ ), it can be clearly observed that the shells of most fragments of hollow spheres are collapsed due to the large space and the thin shell, like deflated balloons, but not broken. When $R$ continues rising to $10^{\circ} \mathrm{C} / \mathrm{min}$ or a higher temperature, the spherical structures broke into pieces (not shown here). In summary, by adjusting the heating rates, we can easily synthesize $\mathrm{MnCo}_{2} \mathrm{O}_{4}$ hollow spheres with multilevel interiors.

In order to further investigate the crystallinity and internal homogeneity, detailed information on the structure and local atomic composition of the $\mathrm{MnCo}_{2} \mathrm{O}_{4}$ yolk-shell submicrospheres was further acquired by high resolution TEM (HRTEM) and energy dispersive X-ray spectroscopy (EDX) analysis. The representative HRTEM image of Fig. 3(b) at the edge of a single particle (marked in Fig. 3(a)) displays distinct lattice fringes with an interplanar distance of $4.75 \AA$ and $2.90 \AA$, corresponding to the spacings of (111) and (220) planes, respectively, of $\mathrm{MnCo}_{2} \mathrm{O}_{4}$ crystals. The selected area electron diffraction (SAED) pattern (inset in Fig. 3b) indicates the polycrystalline nature of the spheres, and all the diffraction rings can be indexed as (111), (220), (311), (400), (511), and (440) planes from the inside out, respectively, corresponding to the XRD patterns. In addition, the chemical compositions of the $\mathrm{MnCo}_{2} \mathrm{O}_{4}$ yolk-shell submicrospheres are confirmed by energy-dispersive X-ray spectroscopy (EDX) analysis (Fig. 3(c)), which indicates an atomic $\mathrm{Mn} / \mathrm{Co}$ ratio of 1:2, wherein the elements $\mathrm{C}$ and $\mathrm{Cu}$ are from the copper grid, and no other impurity is detected. 
The electrochemical properties of the as-prepared yolk-shell spheres were investigated by cyclic voltammetry. As shown in Fig. 4(a), when the electrodes are scanned cathodically from 3.0 to 0.01 $\mathrm{V}$ in the first cycle at a scan rate of $0.1 \mathrm{mV} \mathrm{s}^{-1}$, an intense peak with the characteristics of the reduction potential is located at $\sim 0.57 \mathrm{~V}$, which can be assigned to $\mathrm{Mn}^{2+} / \mathrm{Mn}^{0}$ and $\mathrm{Co}^{3+} / \mathrm{Co}^{0}$. In the following anodic polarization process, one weak peak centered at $1.53 \mathrm{~V}$ could be ascribed to the oxidation of $\mathrm{Mn}^{0} / \mathrm{Mn}^{2+}$. Another broad peak is recorded in the range of 1.8-2.3 V, corresponding to the complex phase transformation of $\mathrm{Co}^{0} / \mathrm{Co}^{2+}$. In the subsequent four cycles, a decrease in the reduction peak intensity could be observed with a shift of the potential $(0.82 \mathrm{~V})$ to the positive direction, which reflects the irreversible electrochemical reaction during the first discharge cycle. ${ }^{22}$ From the second cycle onwards, both the reduction and the oxidation peaks overlap very well, indicating that these two electrodes exhibit good stability and cyclability for the insertion and extraction of lithium ions. Based on the above analysis, the lithium insertion and extraction reactions for our porous $\mathrm{MnCo}_{2} \mathrm{O}_{4}$ electrode are believed to proceed as follows, similar to our previous report: ${ }^{18}$

$$
\begin{aligned}
& \mathrm{MnCo}_{2} \mathrm{O}_{4}+8 \mathrm{Li}^{+}+8 \mathrm{e}^{-} \rightarrow \mathrm{Mn}+2 \mathrm{Co}+4 \mathrm{Li}_{2} \mathrm{O} \\
& \mathrm{Mn}+2 \mathrm{Co}+3 \mathrm{Li}_{2} \mathrm{O} \leftrightarrow \mathrm{MnO}+2 \mathrm{CoO}+6 \mathrm{Li}^{+}+6 \mathrm{e}^{-}
\end{aligned}
$$

Fig. 4(b) shows discharge-charge curves of the electrodes made from the $\mathrm{MnCo}_{2} \mathrm{O}_{4}$ yolk-shell submicrospheres at a current of $400 \mathrm{~mA} \mathrm{~g}^{-1}$ at room temperature in a potential window between $0.01 \mathrm{~V}$ and $3.0 \mathrm{~V}$ (vs. $\mathrm{Li}^{+} / \mathrm{Li}$ ). The initial discharge capacity is $1425 \mathrm{mAh} \mathrm{g}^{-1}$, which is higher than the theoretical value (906 $\mathrm{mAh} \mathrm{g}^{-1}$ ) based on the conversion reaction of Equation (1). Omitting the capacity of the first discharge platform (about $750 \mathrm{mAh} \mathrm{g}^{-1}$ ), the remaining extra capacities of about $675 \mathrm{mAh} \mathrm{g}^{-1}$, corresponding to the two slope ranges, are mainly ascribed to two factors: the formation of the solid electrolyte interface (SEI) film ${ }^{23}$ and the organic polymeric/gel-like layer. ${ }^{24}$ Comparing them, the first one is irreversible, as demonstrated by the following discharge cycles; the latter one originates from the reversible formation/dissolution of an organic polymeric/gel-like layer by electrolyte decomposition, which could deliver an extra capacity through a so-called "pseudo-capacitive behavior". ${ }^{24}$ It can be seen that the initial specific charge capacity is about $1119 \mathrm{mAh} \mathrm{g}^{-1}$, indicating a capacity loss of $306 \mathrm{mAh} \mathrm{g}^{-1}$ and a charging retention of 78.5\%. From the following cycles onwards, the discharge capacity of the platform is about $670 \mathrm{mAh} \mathrm{g}^{-1}$, which is very close to the theoretical capacity $\left(680 \mathrm{mAh} \mathrm{g}^{-1}\right)$ based on the reversible reaction (2). The unique structure with porosity and yolk-shell architecture is also considered as another important factor. Other structures including porous spheres, hollow spheres, shell-in-shell spheres, and yolk-in-double-shell spheres also exhibit the similar shape and plateau except the capacity values, as indicated in Fig. S4 (SI).

As is well known, mesoporous structures can stabilize the structural integrity of electrodes, thus improving the cyclability, while hollow structures can enlarge the contact areas between the electrode and electrolyte, thus improving the specific capacity of the electrode. To determine which structure is most appropriate for anode material, we investigated all these five samples, 
including porous spheres, hollow spheres, yolk-in-shell spheres, shell-in-shell spheres, and yolk-in-double-shell spheres as the targets for electrochemical performance testing. Fig. 4(c) shows the charge/discharge capacity versus cycle number for the electrodes made from the $\mathrm{MnCo}_{2} \mathrm{O}_{4}$ submicrospheres with multilevel interiors at a current density of $400 \mathrm{~mA} \mathrm{~g}^{-1}$. We clearly observe that in the first cycle, the discharge capacities of all these electrodes decrease rapidly, which is due to the irreversible reactions, as mentioned above. Obviously, for the discharge capacity of the first several cycles, the electrode made from yolk-shell spheres possesses the highest capacity; the shell-in-shell spheres take the second place, and then the hollow spheres, yolk-in-double-shell spheres, and porous spheres. These results are almost consistent with the BET results (as shown in Table S1). It can be found that the sample with the larger special surface area possesses the higher discharge capacity. However, with increasing the cycling numbers, the discharge capacities for all these samples decay gradually and it's very common for metal oxides because of the polarization and pulverization of the electrode. Finally, it can retain a stable value after cycling. From the curves of cycling life, we can only conclude that the yolk-shell sphere is the best one among these five samples. The capacity retention curves (defined as: certain cycle discharge capacity $/ 2^{\text {nd }}$ cycle discharge capacity $\times 100 \%$ ), which would reflect the overall application performance, give the clear order of yolk-shell spheres, hollow spheres $>$ mesoporous spheres $>$ shell-in-shell spheres, yolk-in-double shell spheres. Therefore, based on the result above, the yolk-shell sphere shows the best electrochemical performance. The possible reason for this phenomenon is that the yolk-shell spheres not only possess the highest specific surface area, but also maintain the integrity of their hierarchical structure, both of which are beneficial for improving the capacity and cyclability. Compared with the shell-in-shell spheres and the yolk-in-double-shell spheres, the mesoporous ones exhibited smaller specific surface areas and consequently, lower discharge capacity, but they had more stable structure and better capacity retention. Therefore, we concluded that both high specific surface area and good integrity are two key factors for the micro-/nanostructures as suitable anode materials.

In summary, we have devised a novel two-step method to prepare uniform hollow $\mathrm{MnCo}_{2} \mathrm{O}_{4}$ submicrospheres with multilevel interiors, including mesoporous, hollow, yolk-shell, shell-in-shell and yolk-in-double-shell spheres. The first step involves the facile synthesis of uniform metal-glycolate submicrosphere. In the second step, the MnCo-glycolate submicrospheres are simply annealed in air at different heating rates to generate the unique $\mathrm{MnCo}_{2} \mathrm{O}_{4}$ hierarchical hollow submicrospheres. Interestingly, when tested as anode materials, the $\mathrm{MnCo}_{2} \mathrm{O}_{4}$ submicrospheres with a yolk-shell structure showed the best performance among these multilevel interior structures. In addition, this general route can also be expanded to synthesize other mixed metal oxides with respect to the facile preparation and the high yield of the product.

\section{ASSOCIATED CONTENT}




\section{Supporting Information}

Experimental details, XRD patterns, SEM and TEM images of the precursor, BET surface areas, XPS spectrum and charge/discharge curves. These materials are available free of charge via the Internet at http://pubs.acs.org.

\section{AUTHOR INFORMATION}

\section{Corresponding Author}

* Fax: +61 2 42215731; Tel: +61 2 42981478; E-mail: jiazhao@uow.edu.au. (Wang, J. Z.)

* Fax: +86 531 88363018; Tel: +86 531 88363018; E-mail:_chexsl@sdu.edu.cn. (Xiong, S. L.)

\section{Notes}

The authors declare no competing financial interest.

\section{ACKNOWLEDGMENTS}

The authors gratefully acknowledge the financial supports provided by the National Basic Research Program of China (the 973 Project of China, No. 2011CB935901), National Natural Science Fund of China (No. 21371108), Shandong Provincial Natural Science Foundation for Distinguished Young Scholar (JQ201304), the Independent Innovation Foundations of Shandong University (No.2012ZD008), the National Science Foundation of Shandong Province (No. ZR2012BM018), start-up funding for new faculty in Shandong University, Opening Project of CAS Key Laboratory of Materials for Energy Conversion, China Postdoctoral Science Foundation (No. 2013M541904) and the Australian Research Council (ARC) through a Discovery Project (DP110103909). Many thanks also go to Dr. T. Silver for critical reading of the manuscript.

\section{REFERENCES}

(1) Yin, Y. D.; Rioux, R. M.; Erdonmez, C. K.; Hughes, S.; Somorjai, G. A.; Alivisatos, A. P. Science 2004, 304, 711.

(2) Wang, Z. Y.; Wang, Z. C.; Wu, H. B.; Lou, X. W. Sci. Rep. 2013, 3, 1391.

(3) Gao, J. H.; Liang, G. L.; Zhang, B.; Kuang, Y.; Zhang, X. X.; Xu, B. J. Am. Chem. Soc. 2007, 129, 1428.

(4) Pan, A. Q.; Wu, H. B.; Yu, L.; Lou, X. W. Angew. Chem., Int. Ed. 2013, 52, 2226.

(5) Xiong, S. L.; Zeng, H. C. Angew. Chem., Int. Ed. 2012, 51, 949. 
(6) Lai, X. Li, J.; Korgel, B. A.; Dong, Z.; Li, Z.; Su, F.; Du, J.; Wang, D. Angew. Chem., Int. Ed. 2011, 50, 2738.

(7) Xu, H. L.; Wang, W. Z. Angew. Chem., Int. Ed. 2007, 46, 1489.

(8) Wang, X.; Wu, X. L.; Guo, Y. G.; Zhong, Y. T.; Cao, X. Q.; Ma, Y.; Yao, J. N. Adv. Funct. Mater. 2010, 20, 1680.

(9) Guan, J. G.; Mou, F. Z.; Sun, Z. G.; Shi, W. D. Chem. Commun. 2010, 46, 6605.

(10) Zhou, L.; Xu, H. Y.; Zhang, H. W.; Yang, J.; Hartono, S. B.; Qian, K.; Zou, J.; Yu, C. Z. Chem. Commun. 2013, 49, 8695.

(11) Dong, Z. H.; Lai, X. Y.; Halpert, J. E.; Yang, N. L.; Yi, L. X.; Zhai, J.; Wang, D.; Tang, Z. Y.; Jiang, L. Adv. Mater. 2012, 24, 1046.

(12) Zhou, L.; Wu, H. B.; Zhu, T.; Lou, X. W. J. Mater. Chem. 2012, 22, 827.

(13) Zhou, L.; Zhao, D. Y.; Lou, X. W. Adv. Mater. 2012, 24, 745.

(14) Zhang, G. Q.; Yu, L.; Wu, H. B.; Hoster, H. E.; Lou, X. W. Adv. Mater. 2012, 24, 4609.

(15) Li, J. F.; Xiong, S. L.; Liu, Y. R.; Ju, Z. C.; Qian, Y. T. ACS Appl. Mater. Interfaces 2013, 5, 981.

(16) Li, J. F.; Xiong, S. L.; Li, X. W.; Qian, Y. T. J. Mater. Chem. 2012, 22, 23254.

(17) Li, J. F.; Wang, J. Z.; Wexler, D.; Shi, D. Q.; Liang, J. W.; Liu, H. K.; Xiong, S. L.; Qian, Y. T. J. Mater. Chem. A 2013, 1, 15292.

(18) Li, J. F.; Xiong, S. L.; Li, X. W.; Qian, Y. T. Nanoscale 2013, 5, 2045.

(19) Hu, L.; Zhong, H.; Zheng, X. R.; Huang, Y. M.; Zhang, P.; Chen, Q. W. Sci. Rep. 2013, 2, 986.

(20) Sing, K. S. W.; Everett, D. H.; Haul, R. A. W.; Moscou, L.; Pierotti, R. A.; Rouquerol, J.; Siemieniewska, T. Pure Appl. Chem. 1985, 57, 603.

(21) Vinu, A.; Sawant, D. P.; Ariga, K.; Hartmann, M.; Halligudi, S. B. Microporous Mesoporous Mater. 2005, 80, 195.

(22) Sharma, Y. G.; Rao, V. S.; Chowdari, B. V. R. Adv. Funct. Mater. 2007, 17, 2855.

(23) Munichandraiah, N.; Scanlon, L. G.; Marsh, R. A. J. Power Sources 1998, 72, 203.

(24) Laruelle, S.; Grugeon, S.; Poizot, P.; Dolle, M.; Dupont, L.; Tarascon, J. M. J. Electrochem. Soc. 2002, 149, A627. 


\section{Figures:}

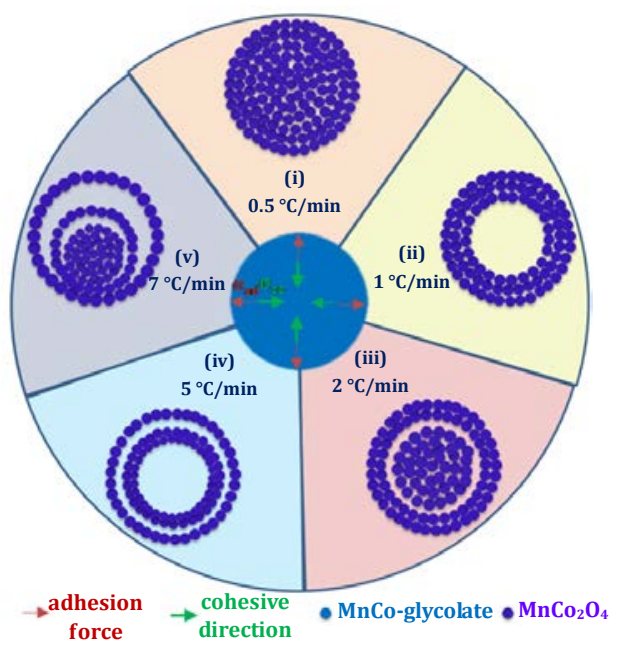

Scheme 1. Formation process of $\mathrm{MnCo}_{2} \mathrm{O}_{4}$ hollow submicrospheres with different interiors calcined at different heating rates from MnCo-glycol precursors: (i) mesoporous spheres $\left(0.5^{\circ} \mathrm{C} / \mathrm{min}\right)$; (ii) hollow spheres $\left(1.0^{\circ} \mathrm{C} / \mathrm{min}\right)$; (iii) yolk-shell spheres $\left(2.0^{\circ} \mathrm{C} / \mathrm{min}\right)$; (iv) shell-in-shell spheres $\left(5.0^{\circ} \mathrm{C} / \mathrm{min}\right)$; (v) yolk-in-double-shell structures $\left(7.0^{\circ} \mathrm{C} / \mathrm{min}\right)$.
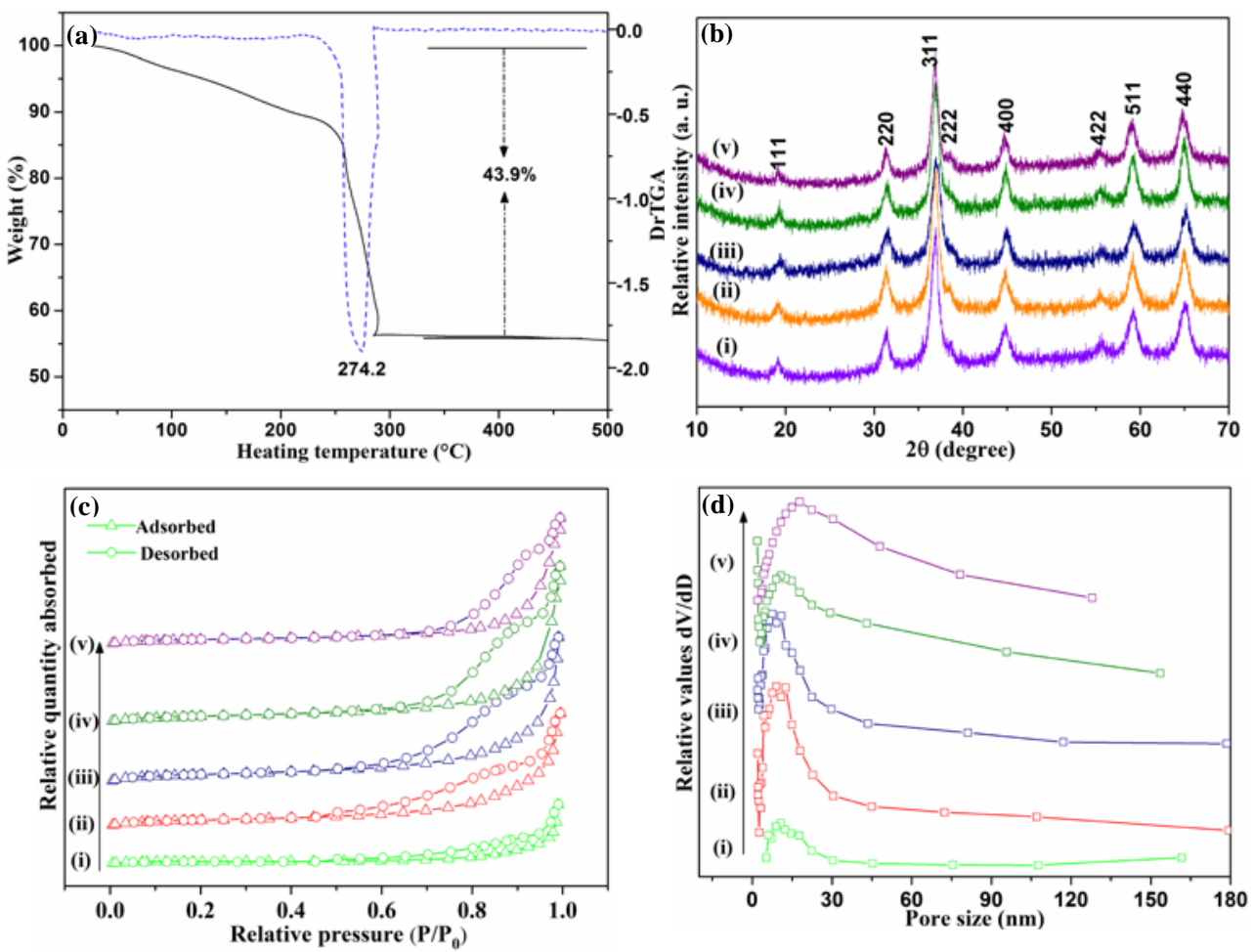

Fig. 1. TGA (solid line) and DrTGA (dashed line) curves (a) for the MnCo-glycolate precursor calcined in air. (b) Typical XRD patterns, (c) nitrogen physisorption isotherms, and (d) pore size distributions of the five samples calcined at different heating rates from $0.5^{\circ} \mathrm{C} / \mathrm{min}$ to $7.0^{\circ} \mathrm{C} / \mathrm{min}$. 


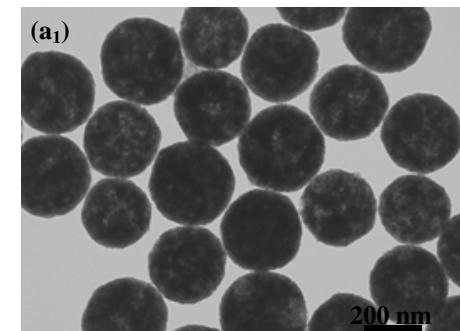

(a)

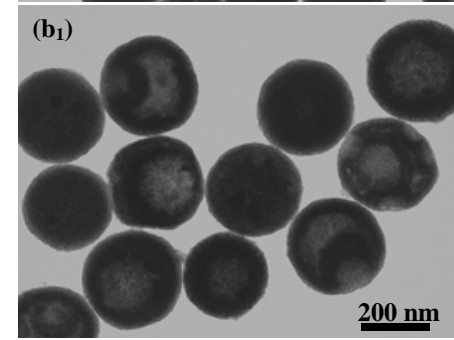

$\left(\mathbf{b}_{2}\right)$
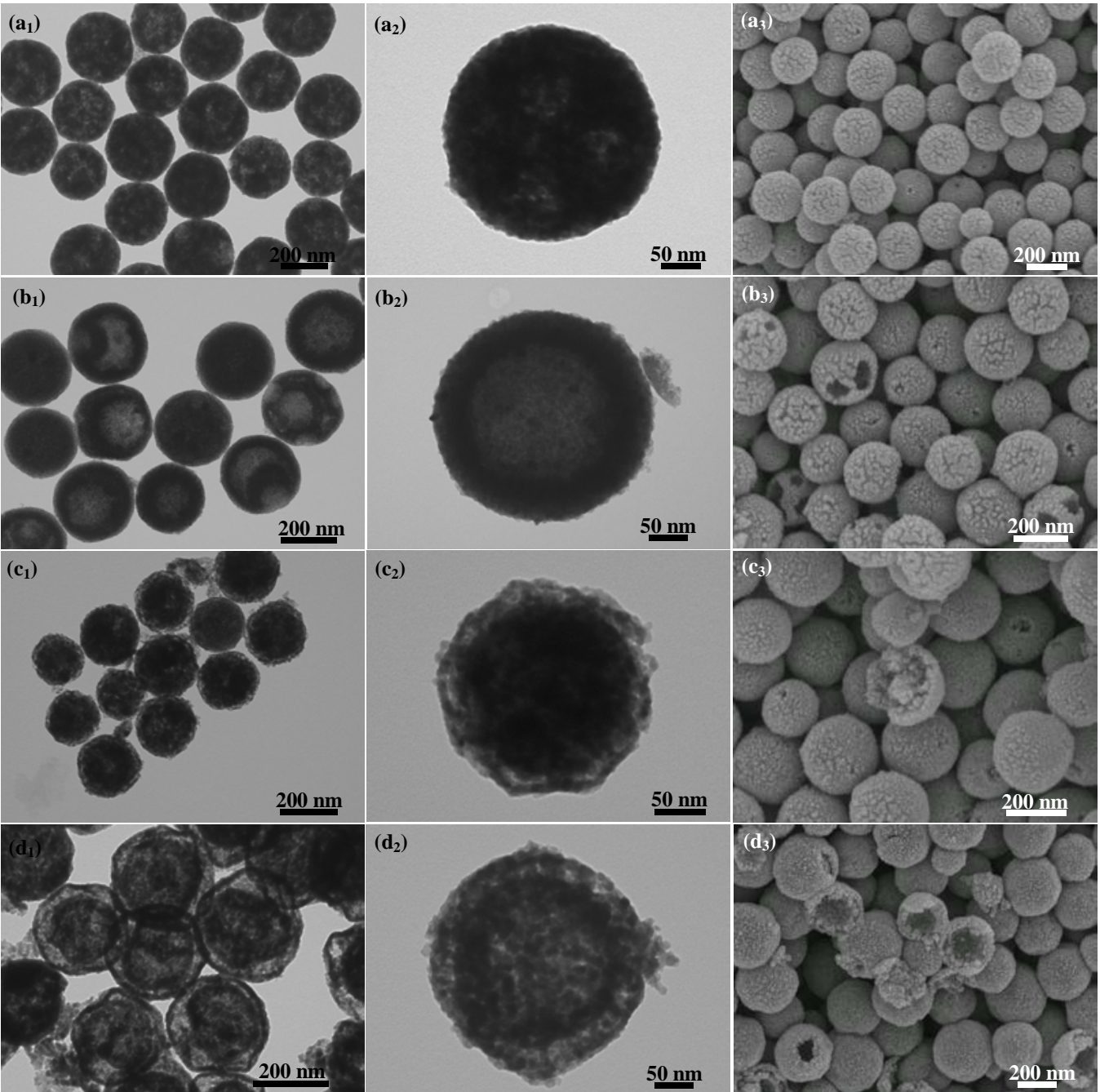

$\left(c_{2}\right)$
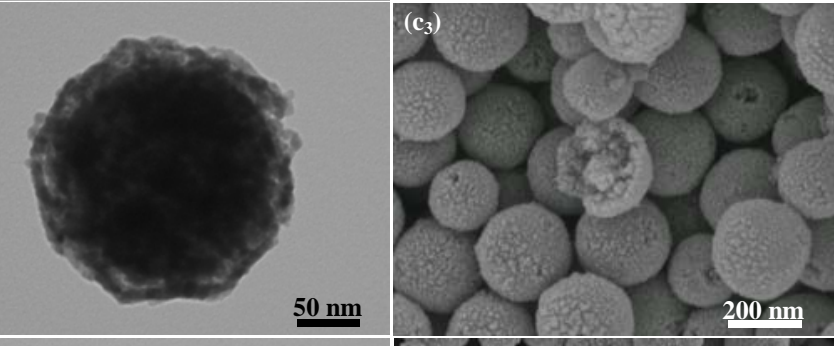

$\left(d_{2}\right)$
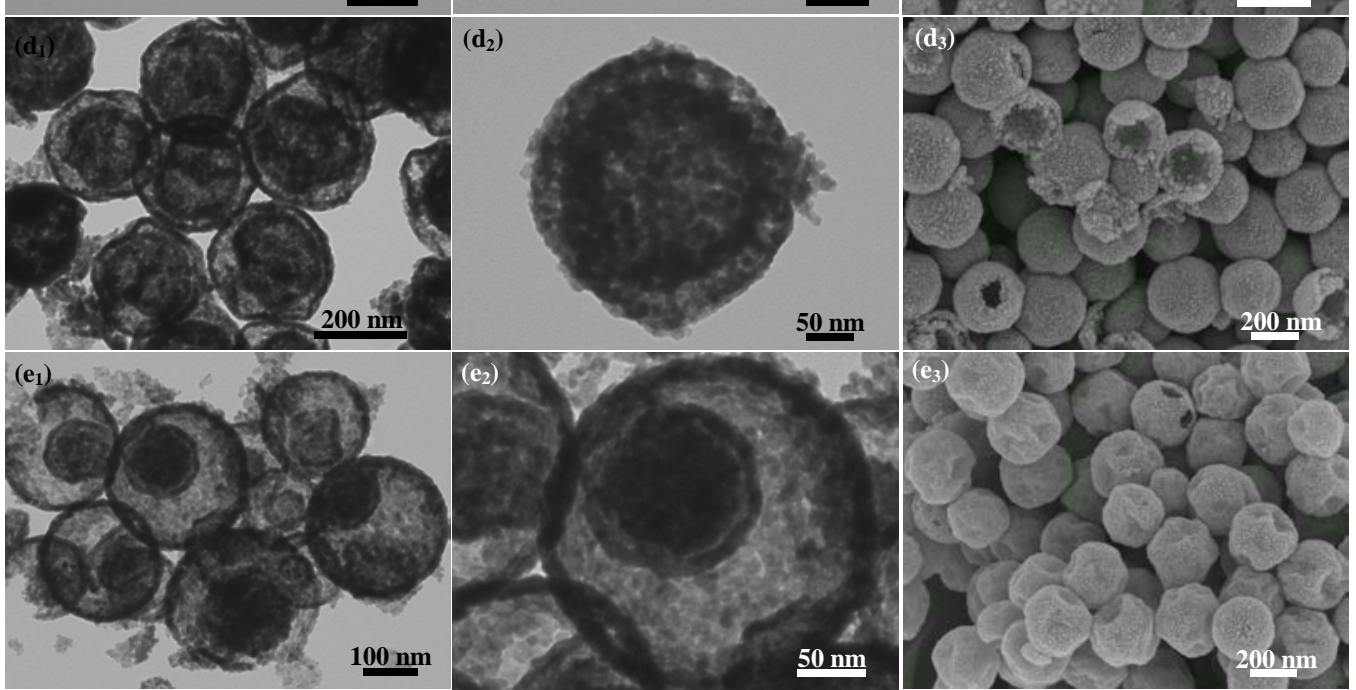

Fig. 2. TEM $\left(\mathrm{a}_{1}-\mathrm{e}_{1}, \mathrm{a}_{2}-\mathrm{e}_{2}\right)$ and FESEM $\left(\mathrm{a}_{3}-\mathrm{e}_{3}\right)$ images of $\mathrm{MnCo}_{2} \mathrm{O}_{4}$ submicrospheres with multilevel interiors annealed at $400{ }^{\circ} \mathrm{C}$ in air by controlling different heating rates $(R)$ : $\left(\mathrm{a}_{1}-\mathrm{a}_{3}\right)$ mesoporous spheres $\left(0.5^{\circ} \mathrm{C} / \mathrm{min}\right)$; $\left(\mathrm{b}_{1}-\mathrm{b}_{3}\right)$ hollow spheres $\left(1.0^{\circ} \mathrm{C} / \mathrm{min}\right)$; $\left(\mathrm{c}_{1}-\mathrm{C}_{3}\right)$ yolk-shell spheres $\left(2 .{ }^{\circ} \mathrm{C} / \mathrm{min}\right)$; $\left(\mathrm{d}_{1}-\mathrm{d}_{3}\right)$ shell-in-shell spheres $\left(5.0{ }^{\circ} \mathrm{C} / \mathrm{min}\right)$; $\left(\mathrm{e}_{1}-\mathrm{e}_{3}\right)$ yolk-in-double- shell spheres $\left(7.0^{\circ} \mathrm{C} / \mathrm{min}\right)$. 

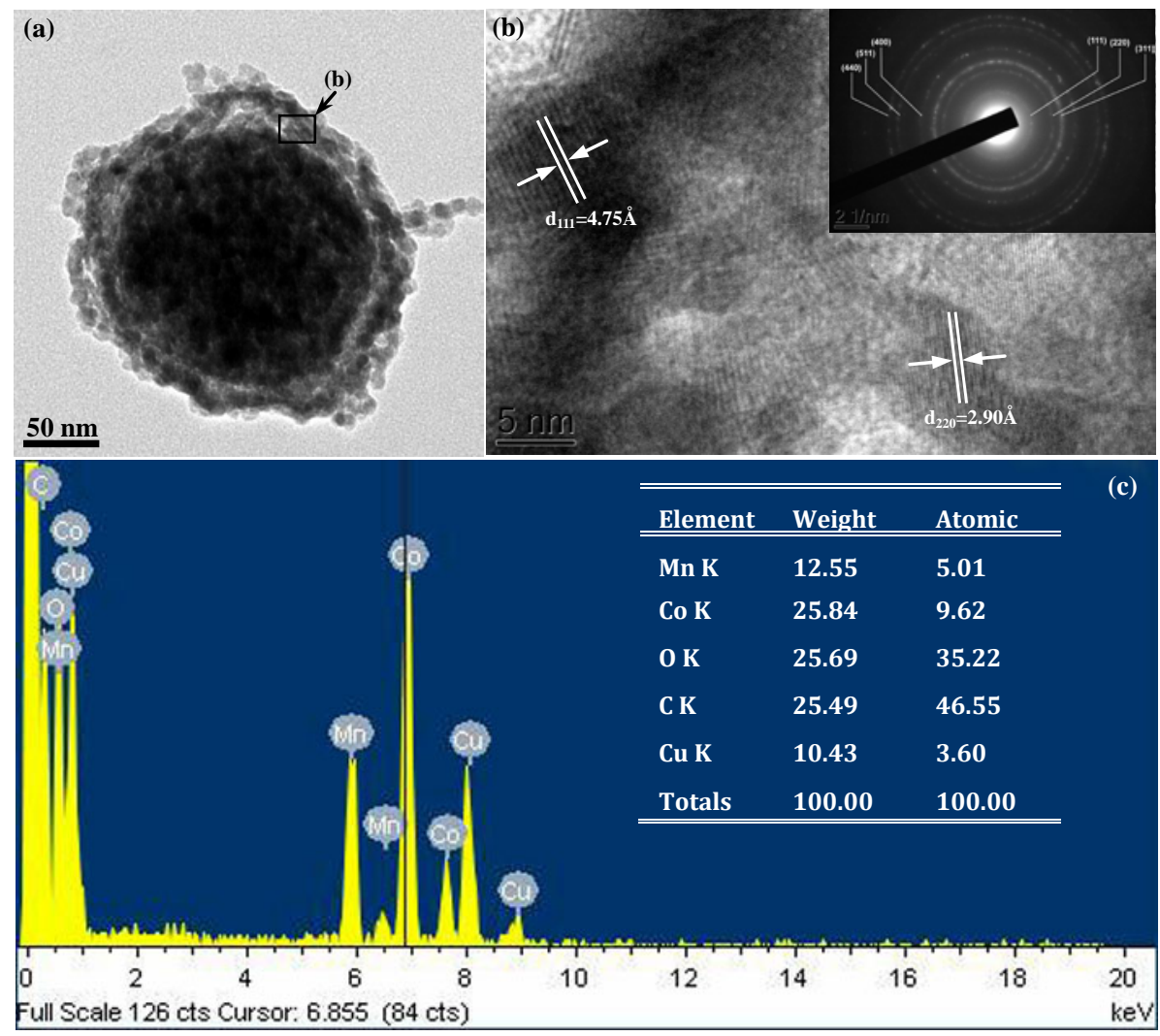

Fig. 3. TEM image (a) of a single yolk-shell submicrosphere. HRTEM image (b) at the edge of the submicrosphere with the corresponding SAED pattern (the inset) and (c) the corresponding EDX spectrum.
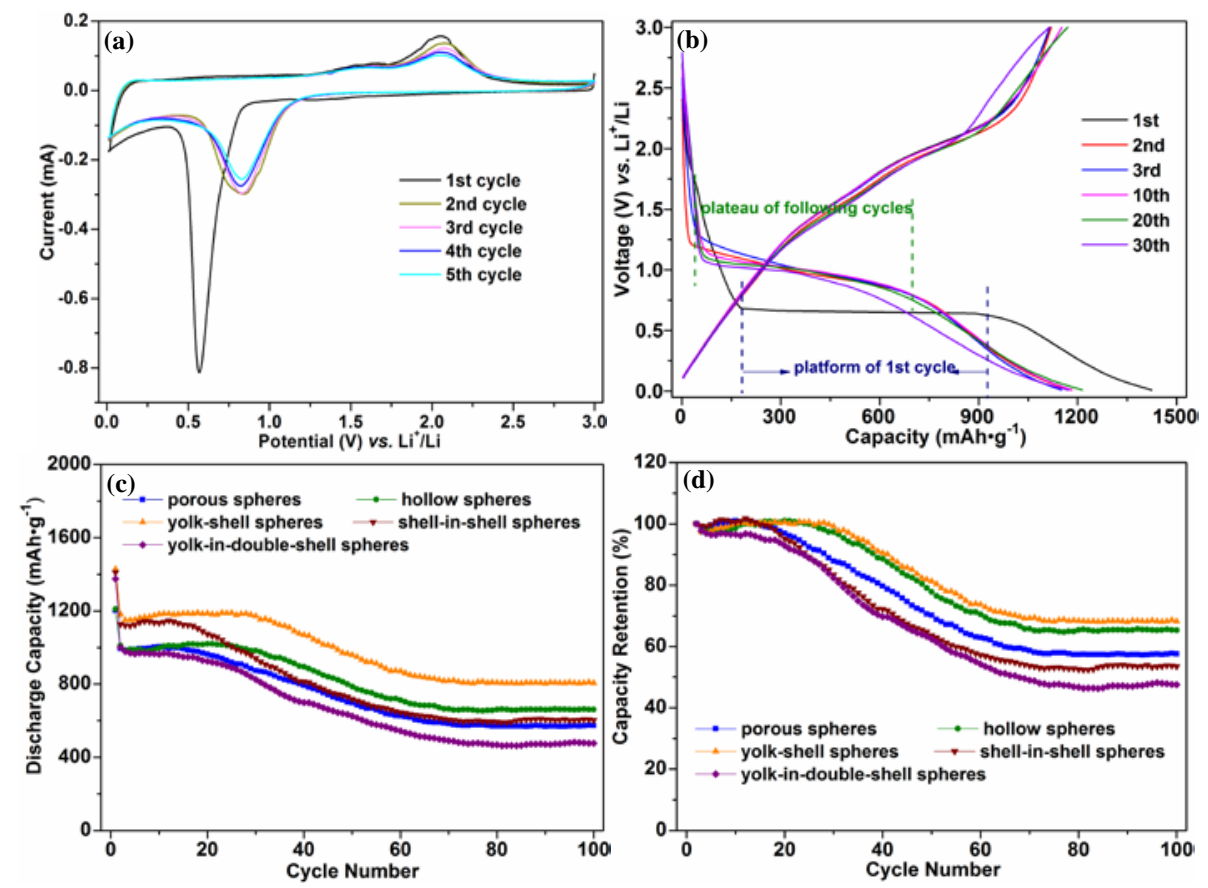

Fig. 4. The first five consecutive cyclic voltammograms (a) at a scan rate of $0.1 \mathrm{mV} / \mathrm{s}$ in the voltage range of 0.01-3.0 V vs. $\mathrm{Li}^{+} / \mathrm{Li}$, and discharge/charge profiles for selected cycles (b) of the electrode made from yolk-shell submicrospheres. (c) Cycling performance and (d) capacity retention of the electrodes composed of mesoporous spheres, hollow spheres, yolk-shell spheres, shell-in-shell spheres and yolk-in-double-shell spheres, respectively. 


\section{Tables of Contents (TOC) Image}

The following graphic (approx $3.6 \mathrm{~cm} \times 8.4 \mathrm{~cm}$ ) will be used for the TOC on the ACS website:

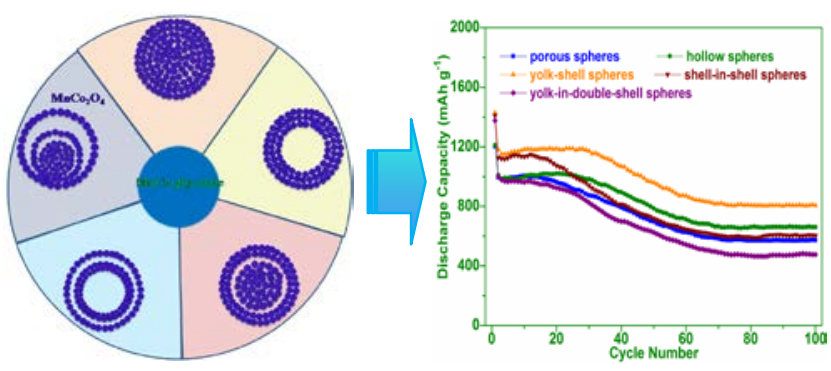

